\title{
CONHECIMENTO DIDÁTICO DO CONTEÚDO DE PROFESSORES DE CIÊNCIAS DA NATUREZA E MATEMÁTICA: ANÁLISE A PARTIR DOS DESENHOS CURRICULARES
}

\author{
Diana Lineth Parga Lozano* \\ Gabriela Bueno Denari** \\ Gabriela Castro Silva Cavalheiro**
}

RESUMO: O tema conhecimento didático do conteúdo (CDC) é campo de estudo que contribui para a formação de professores e a melhoria da qualidade educacional. Assim, objetivou-se caracterizar o CDC de professores de ciências da natureza e matemática quando estes fazem desenhos curriculares e propor critérios para formação docente que permitam desenvolver currículos mais desejáveis. Realizou-se uma pesquisa descritiva qualitativa, focalizada na análise de conteúdo, sobre unidades e/ou projetos didáticos construídos por dois grupos de professores em formação pós-gradual. A maioria dos desenhos analisados está centrada nos conhecimentos disciplinares, abordando pouco o conhecimento psicopedagógico e deixando de lado os conhecimentos metadisciplinares e contextuais. Portanto, é necessária uma formação docente voltada para a articulação dos saberes enunciados com a prática pedagógica.

Palavras-chave: Conhecimento didático do conteúdo. Desenho curricular. Unidades didáticas.

\section{CONOCIMIENTO DIDÁCTICO DEL CONTENIDO DE PROFESORES DE CIENCIAS DE LA NATURALEZA Y MATEMÁTICAS: ANÁLISIS A PARTIR DE LOS DISEÑOS CURRICULARES}

RESUMEN: El tema conocimiento didáctico del contenido (CDC) es un área de estudio que contribuye a la formación de profesores y a la mejoría de la calidad educativa. Así, se tiene como objetivo caracterizar el CDC de profesores de ciencias de la naturaleza y matemáticas cuando estos hacen diseños curriculares, y proponer criterios para la formación docente que permitan desarrollar currículos más apropiados. Se realizó una investigación descriptiva cualitativa, focalizada en el análisis de contenido, acerca de las unidades y/o proyectos didácticos elaborados por dos grupos de profesores en formación de posgrado. La mayoría de los diseños analizados está centrada en los conocimientos disciplinarios se abordó poco el conocimiento psicopedagógico y no se consideraron los conocimientos metadisciplinarios y contextuales. Por lo tanto, es necesaria una formación docente orientada hacia la articulación de los saberes enunciados con la práctica pedagógica.

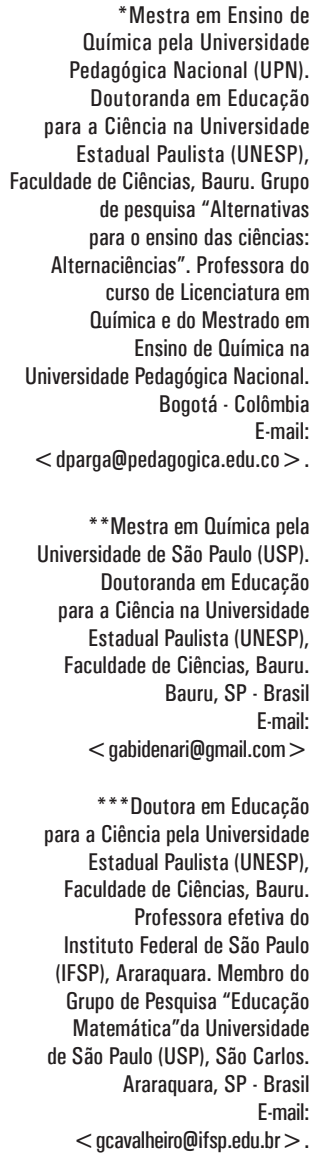

*Mestra em Ensino de Química pela Universidade Pedagógica Nacional (UPN). Doutoranda em Educação para a Ciência na Universidade Estadual Paulista (UNESP), Faculdade de Ciências, Bauru. Grupo de pesquisa "Alternativas para 0 ensino das ciências: Alternaciências". Professora do curso de Licenciatura em Química e do Mestrado em Ensino de Química na Universidade Pedagógica Nacional. Bogotá - Colômbia E-mail:

< dparga@pedagogica.edu.co >

* * Mestra em Química pela Universidade de São Paulo (USP). Doutoranda em Educação para a Ciência na Universidade Estadual Paulista (UNESP), Faculdade de Ciências, Bauru. Bauru, SP - Brasil E-mail:

< gabidenari@gmail.com>

* * Doutora em Educacãa para a Ciência pela Universidade Estadual Paulista (UNESP), Faculdade de Ciências, Bauru. Professora efetiva do Instituto Federal de São Paulo (IFSP), Araraquara. Membro do Grupo de Pesquisa "Educação Matemática"da Universidade de São Paulo (USP), São Carlos. Araraquara, SP - Brasil E-mail:

< gcavalheiro@ifsp.edu.br > 
Palabras clave: Conocimiento didáctico del contenido. Diseño curricular. Unidades didácticas.

PEDAGOGICAL CONTENT KNOWLEDGE OF NATURE SCIENCES AND MATHEMATICS TEACHERS: ANALYSIS BASED ON CURRICULUM DESIGN

ABSTRACT: The pedagogical contentknowledge (PCK) is a field of study that contributes to teacher training and improving educational quality. In this sense, the objective was to characterize the natural science and mathematics teachers' PCK when they make curricular designs and propose criteria for teacher training in order to develop more desirable curricula. We conducted a qualitative descriptive research, focused on content analysis on units and / or educational projects built by two groups of postgraduate teachers. Most of the analyzed curricular designs are focused on disciplinary knowledge, little addressing the psycho-pedagogical knowledge and leaving aside metadisciplinary and contextual knowledge. Therefore, a teacher's training focused for the articulation of outlined knowledge with the pedagogical practice is required.

Keywords: Pedagogical content knowledge. Curriculum design. Instructional design. 


\section{INTRODUÇÃO}

As pesquisas sobre o Conhecimento Didático do Conteúdo (CDC) emergem no contexto das linhas dos saberes docentes, trabalhada na década de 1980, pelos movimentos da profissionalização, do cognitivismo, dos enfoques etnográficos e interacionistas, interessados nos saberes dos atores sociais. Nestes, os saberes docentes são considerados plurais, compostos e heterogêneos, uma vez que o exercício do trabalho, os conhecimentos e as suas manifestações são diversificados e têm diferentes procedências, o que supõe também uma natureza diferente (TARDIF, 2004).

O que se descreve neste artigo é parte dessa diversidade, na busca de encontrar os critérios que se têm em comum, para, finalmente, descrever os conhecimentos/ crenças que predominam quando os professores fazem seus desenhos curriculares e sua relação com o CDC. Assim, Shulman (1987) propõe um tipo de saber docente que é autônomo, o chamado, dentro da literatura norte-americana, pedagogicalcontentknowledge (PCK). Oautor o denomina como um dos sete saberes de base para o ensino, colocando-o em igualdade com o conhecimento do conteúdo, o conhecimento pedagógico geral, o conhecimento do planejamento, o conhecimento dos estudantes, o conhecimento dos contextos educativos e o conhecimento filosófico e histórico da educação. $\mathrm{O}$ PCK começou como uma linha de pesquisa, que depois foi transformando-se em um modelo teórico para entender o ensino dos conteúdos, originando aproximações em áreas do conhecimento escolar, e que no contexto latino-americano é chamado CDC, dada a diferença entre o pedagógico e o didático (PARGA; MORA, 2014).

Nesse sentido, o objetivo do presente trabalho foi caracterizar o CDC de professores de ciências da natureza e matemática quando estes fazem desenhos curriculares e, a partir do encontrado, propor critérios para formação docente que permitam desenvolver currículos mais desejáveis.

\section{CONHECIMENTO DIDÁTICO DO CONTEÚDO (CDC)}

OCDC faz parte do conhecimento profissionaldo professore, concordando com Mora e Parga (2014), é um conhecimento próprio do professorado, que está sustentado em produzir emergências de conteúdos à medida das necessidades contextuais e históricas para cada aula e para cada docente. O CDC

[...] é um conhecimento profissionalizado que resulta da hibridação de diferentes tipos de conhecimentos e crenças pessoais do professor; é expressado tanto em suas teorias implícitas quanto em suas rotinas e guias de ação. A integração do conhecimento é própria do campo didático, já que está orientado ao ensino de conteúdos, e seu resultante é uma emergência da combinatória de distintos elementos que se encontram fazendo parte dos quatro componentes descritos em um trabalho prévio (MORA; PARGA, 2008): o conhecimento disciplinar ou conhecimento da matéria (CDM); o histórico-epistemológico (CHE); o psicopedagógico (CSP) e; o conhecimento do contexto escolar (CCE), expressam-se nos saberes metadisciplinares, disciplinares e experienciais. Como temos dito, a integração dos componentes com cada uma das categorias não é igual e depende do tema ao ensinar como do domínio de cada professor, pelo que é possível não só variações na proporção de cada um dos componentes, como a exclusão de um ou vários deles. (PARGA; MORA, 2014, p. 337). 
Para Marcelo (2009), o CDC é um elemento central dos saberes do docente, pois

[...] representa a combinação adequada entre o conhecimento da matéria a ser ensinada e o conhecimento pedagógico e didático relativo a como ensiná-la. Nos últimos anos vem-se trabalhando nos diferentes contextos educativos para elucidar quais são os componentes desse tipo de conhecimento profissional do ensino. O conhecimento didático do conteúdo, como linha de pesquisa, representa a confluência de esforços de pesquisadores didáticos e de pesquisadores de matérias específicas preocupados com a formação dos professores. $\mathrm{O}$ conhecimento didático do conteúdo nos conduz a um debate no tocante à forma de organização e de representação do conhecimento, através de analogias e metáforas. Aponta a necessidade de que os professores em formação adquiram um conhecimento experiente do conteúdo a ser lecionado, para que possam desenvolver um ensino que propicie a compreensão dos alunos.(MARCELO, 2009, p. 119).

Assim, o CDC transcende seu significado para mostrar seu potencial em três sentidos: a) como marco teórico importante para formação do professorado de ciências; b)para elaboração de materiais curriculares e; c) como marco de investigação didática. Portanto, é possível que exista uma distinção entre o CDC como um conceito educativo orientado pela integração dos conteúdos para fazêlos ensináveis e o CDC como um enfoque teórico do conhecimento sustentado nas didáticas específicas como, por exemplo, a didática da química, articulada aos modelos didáticos do professorado que são fundamentais nos processos formativos dos docentes (PARGA; MORA, 2014).

O CDC é um conhecimento articulador e emergente que lhe ajudaria a consolidar uma melhor identidade profissional ao professor e, portanto, auxiliaria a enfrentar os desafios citados por Marcelo (2009): as emoções, pois desde a formação inicial, lhes ajudam a crer o que é ensinar; as crenças, influenciadas pelas experiências; os conteúdos, porque cada um é diferente na forma de ser ensinado; a epistemologia da prática de ensino; trabalhar em equipe; querer ensinar; construir carreira profissional; definir as responsabilidades do professor; deixar de ver o professor como consumidor de pesquisa e informação e sendo "capacitado"; ter um modelo de profissionalismo; usar as tecnologias e; ter novas fontes educacionais.

O professor de ciências naturais, por exemplo, ao planejar seu ensino, não deve atuar de forma espontânea, porque é um profissional da docência da ciência natural. Portanto, ele começa, ao planejar seu ensino, usando os saberes no sentido de Tardif (2004): o saber, no qual estão os conhecimentos acadêmicos ou disciplinas como a ciência natural, pedagogia, didática da ciência e todas as necessárias na sua interação - epistemologia, história, sociologia, etc.-; o saber fazer, tais como os modelos didáticos, as estratégias para ensinar ciência natural, organizar os grupos ou propor trabalhos em forma individual e; o saber ser, que se relaciona mais na implementação dos desenhos curriculares e o que acontece na própria ação. Ainda, desde esta perspectiva faltariam critérios importantes como os propostos por Mora e Parga $(2008,2014)$ que ajudariam a consolidar um melhor desenho curricular. Tais critérios estão apresentados no Quadro1. 
Quadro 1 - Categorias e componentes do CDC para se considerar no desenho curricular

\begin{tabular}{|c|c|}
\hline Categorias do CDC & \multicolumn{1}{c|}{ Componentes para as categorias do CDC } \\
\hline $\begin{array}{c}\text { Conhecimento / } \\
\text { Crenças do } \\
\text { Disciplinar }\end{array}$ & $\begin{array}{l}\text { Pode ser o conteúdo substantivo e o conteúdo sintático: o substantivo } \\
\text { (declarativo) é o corpo inter-relacionado de conceitos, teorias, } \\
\text { paradigmas da disciplina. O sintático (procedimental) são os métodos, } \\
\text { instrumentos da disciplina, para construir seu conhecimento, como } \\
\text { são introduzidos e aceitos na comunidade científica. }\end{array}$ \\
\hline $\begin{array}{c}\text { Conhecimento / } \\
\text { Crenças do }\end{array}$ & $\begin{array}{l}\text { Mecanismos de produção do conhecimento; os obstáculos } \\
\text { epistemológicos; as formas de vida das comunidades científicas; os } \\
\text { debates e controvérsias; as revoluções científicas e experimentos } \\
\text { cruciais; as biografias, análises de textos originais; interações da } \\
\text { disciplina com a sociedade, a tecnologia, a política, etc. }\end{array}$ \\
\hline $\begin{array}{c}\text { Conhecimento / } \\
\text { Crenças do }\end{array}$ & $\begin{array}{l}\text { Podem ser: as teorias educativas; o conhecimento do currículo; } \\
\text { os modelos de desenvolvimento e aprendizagem do alunado; } \\
\text { concepçóes alternativas, modelos mentais; estratégias de ensino; } \\
\text { metodologias e formas de organização dos grupos; critérios e } \\
\text { formas de avaliação, entre outros. }\end{array}$ \\
\hline $\begin{array}{c}\text { Psicopedagógico } \\
\text { Conhecimento / } \\
\text { Crenças do } \\
\text { Contexto }\end{array}$ & $\begin{array}{l}\text { Relacionado com: Onde se ensina? A quem ensinar? As normas de } \\
\text { funcionamento institucional escolar. Normativa nacional e local. } \\
\text { Configuração cultural, política, ideológica, entre outras, e próprias } \\
\text { da instituição escolar. }\end{array}$ \\
\hline
\end{tabular}

Fonte: Adaptado de Mora e Parga (2014, p. 113-114).

\section{UNIDADES DIDÁTICAS (UD) E SEQUÊNCIAS DE ENSINO}

A unidade didática (UD) é uma elaboração do professor que pode identificar a consolidação de grande parte dos seus saberes, em que é refletida sua profissionalidade, suas concepções, seus interesses, sua identidade; em outras palavras, seu CDC, o qual vai ser próprio para cada tema que ele vai ensinar e para cada grupo de alunos. A seguir são descritas outras características das UD e sua relação com as sequências de ensino.

Em consonância com Campanario e Moya (1999), a UD é um desenho microcurricular que envolve uma análise didática, uma seleção de objetivos e uma seleção de estratégias e formas de avaliar; favorecendo a construção de novos conhecimentos escolares em relação a uma temática determinada. Da mesma forma, para Torres (1994), uma UD é um projeto curricular concreto ou uma proposta de trabalho que abarca um questionamento sobre o que se quer ensinar, além de requerer um diagnóstico em que são determinados os interesses dos estudantes, o contexto sociocultural e os recursos da instituição. Para este autor, o desenho da unidade implica a definição de metas, a escolha de um tópico, de um planejamento de investigação e o trabalho em equipe.

De acordo com Sanmartí (2000) e Campanario e Moya (1999), a UD se constrói considerando quatro momentos: o primeiro corresponde às atividades de iniciação;o segundo, às atividades de desenvolvimento;o terceiro são as atividades 
de aplicação e; o quarto, a avaliação. Há de se dizer que estes momentos não são para abordar de forma esquemática, somente são enunciados como aspectos que devem se ter em consideração.

Além disso, no momento de organizar uma UD para ensinar determinados conteúdos próprios dos saberes químicos, ou matemáticos, por exemplo, devem se considerar, essencialmente os seguintes aspectos: elementos curriculares nos quais se inscreve a proposta; características da proposta curricular: o que, como e quando ensinar e avaliar e;o domínio conceitual da disciplina.

Segundo Mosquera, Mora e García (2003), as UD são unidades de programação, de desenho e desenvolvimento do ensino, e são, portanto, uma forma de organizar os programas escolares que têm capacidade para integrar conteúdos diversos e de estruturar períodos relativamente longos da atividade escolar. Seu desenho se assume como projeto curricular em profundidade que orienta e facilita o desenvolvimento prático,obedece a uma necessidade sentida de um coletivo de profissionais da educação e ao ensino das disciplinas no interior de uma instituição escolar. Em seu desenho consideram-se seis perguntas básicas resumidas na Figura 1, e que podem ser respondidas pelos professores ao fazer o desenho curricular em forma de UD e/ou sequência de ensino.

Figura 1 - Elementos do currículo para considerar no desenho de unidades didáticas

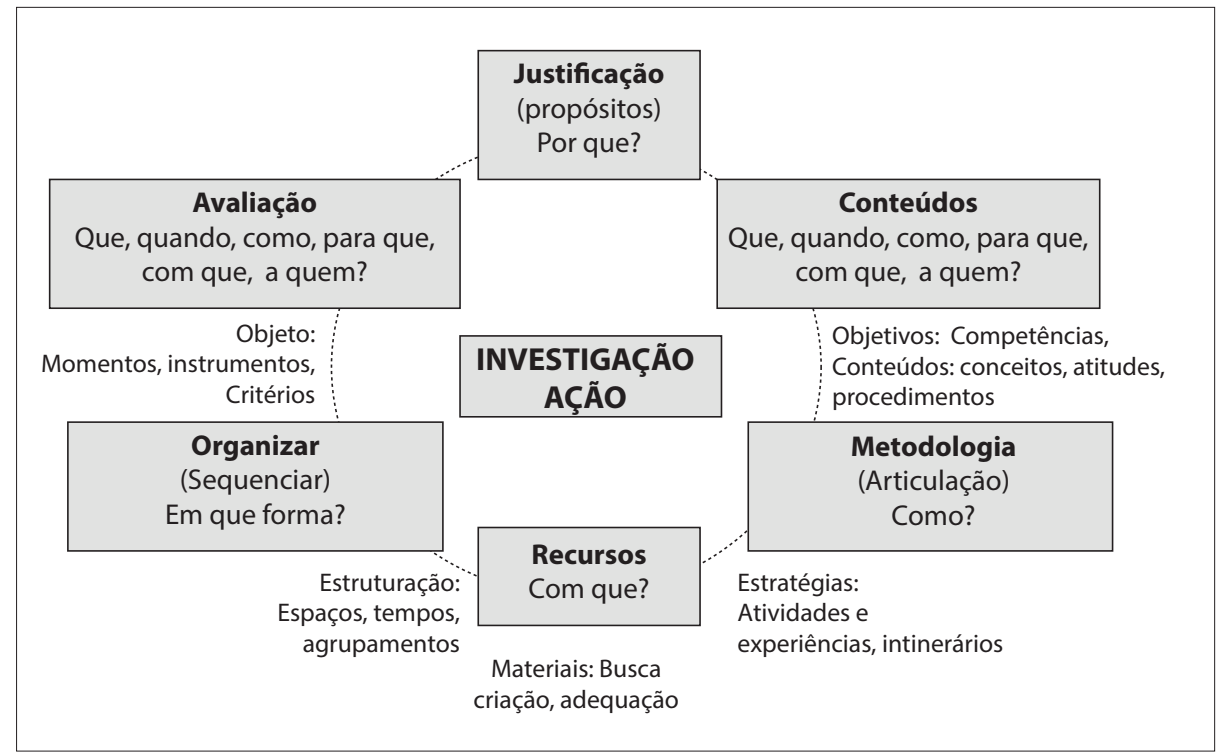

Fonte: Adaptado de Mosquera, Mora e García (2003, p. 201).

Segundo Cañal (2000), as sequências de ensino não são um conglomerado de atividades justapostas sem critério de organização. Dentro de um enfoque sistêmico da aula, o autor as define como atividades propostas dentro das UD, tendo estratégias de ensino que estão relacionadas com o conhecimento estratégico do professor quando é um profissional. Assim, um bom desenho curricular é aquele que mais atende às diversas necessidades dos alunos (SANMARTÍ, 2000). Portanto, é preciso formar professores que tomem decisões refletidas sobre o desenho das UD. 
Com o objetivo de superar os problemas de ensino e aprendizagem das ciências naturais e da matemática, têm sido desenvolvidos modelos didáticos. Neste sentido, Caamaño (2011) afirma que atualmente há sequências didáticas e UD a partir de perspectivas como a contextualização, indagação, modelização e argumentação, aportando resultados importantes às pesquisas didáticas; no entanto, ainda se desenvolvem de forma desarticulada.

Couzo (2011, citada por CAAMAÑO, 2011) destaca que a modelização auxilia na construção de modelos escolares a partir dos modelos mentais dos alunos e, frente ao enfoque baseado na aprendizagem em contexto, afirma que este possibilita o debate de aspectos da ciência, tecnologia e sociedade a partir dos quais são introduzidos os conceitos. Sobre a indagação ou investigação ou método didático-indagativo, Caamaño (2012a) afirma que o ensino das ciências pode partir de problemas reais de caráter aplicado e cuja resolução envolve processos de modelização (CAAMAÑO, 2011), por isto é mais fácil encontrar exemplos de sequências didáticas baseadas na indagação, para a construção de modelos, do que a partir da resolução de problemas práticos, tecnológicos ou sociocientíficos. Esse modelo indagativo, de pesquisa ou de ensino por pesquisa ou investigação, tem passado por diversas etapas de evolução (ver Anexo 1, Quadro 2).

A modelização é um enfoque necessário quando o ensino das ciências tem como propósito desenvolver níveis de argumentação a partir do uso das teorias e modelos ensinados, utilizados para interpretar fenômenos e dar explicações desde os modelos ou teorias da ciência e não desde as teorias pessoais. Segundo Caamaño (2011), o enfoque está relacionado com a indagação porque a modelização incorpora o ensino por indagação na etapa de teste de hipóteses ou validação do modelo. Argumentação em si é um critério para avaliar o conhecimento desde as provas existentes, portanto a aprendizagem das ciências deve favorecer a geração de explicações que se fazem desde os modelos mentais que os sujeitos têm construído.

Segundo Caamaño (2012b), na escola há dois tipos de argumentação: a argumentação para educação científica, que é necessária para elaborar conceitos e teorias, e a argumentação para educação cidadã, que permite a abordagem de temas sociocientíficos e ambientais e que tem um caráter transversal e interdisciplinar no currículo.

Portanto, dentro da análise que foi feita no presente trabalho, é possível que sejam evidentes de forma implícita ou explícita o modelo didático que o professor de forma consciente ou não quer desenvolver dentro da UD ou sequência de ensino. A UD responderia a todas as categorias da Figura 1; entretanto a sequência de ensino só responderia a duas ou três destas.

\section{METODOLOGIA}

A presente pesquisa foi realizada segundo metodologia qualitativa descritiva, com enfoque na análise do conteúdo dos documentos que segundo Galeano (2012) permite desestabilizar a inteligibilidade imediata da superfície textual para evidenciar o que está latente. Para isto, foram definidas como unidades de registro a palavra, a frase e o conceito, os quais estiveram inter-relacionados com o sistema de categorias definidas a priori desde o CDC, e tentando abarcar 
aspectos relevantes dos textos para os objetivos da pesquisa. Como unidade de contexto, ou lugares concretos no texto, nos quais estão as unidades de registro, foi usado o parágrafo para localizar as unidades de registro fazendo evidente seu significado e suas condições de produção (GALEANO, 2012). Com a codificação se identificaram presenças, frequências e recorrências. A categorização, ou classificação das unidades de registro, foi feita com critérios estabelecidos, após da leitura geral dos textos de Campo (classificação semântica através de categorias e subcategorias do CDC, ver quadro 1).

Os documentos da análise foram elaborados por dois grupos de professores (Grupo A e Grupo B). Estes se encontravam em processo de formação pós-gradual stricto sensu (mestrado e doutorado) em Educação para a Ciência, durante o primeiro semestre de 2015, em uma universidade pública do Estado de São Paulo (Brasil).

- Grupo A: contém cinco subgrupos com dezessete professores no total; os quais propuseram uma UD ou uma sequência de ensino a partir do modelo de ensino por investigação. Tal modelo foi trabalhado e analisado numa disciplina de pós-graduação, em que os alunos deveriam elaborar UD levando-se o modelo de ensino por investigação em consideração, ou uma mistura dele com outros modelos(ver Quadro 2). As propostas foram analisadas e depois implementadas com alunos de ensino médio de uma escola pública na cidade de Bauru/SP. Portanto, há cinco documentos para análise neste grupo.

- Grupo B: formado por nove subgrupos com vinte e três professores no total, que elaboraram projetos didáticos dentro de uma disciplina de pósgraduação, no qual eles propuseram ensinar algum tema das ciências ou de matemática, a partir dos critérios que quisessem. Neste grupo há nove documentos para análise.

Dos quarenta professores elaboradores das propostas, a maioria (trinta e cinco) é licenciada, enquanto poucos são bacharéis. Quatorze professores são formados em química, onze em biologia (ou ciências naturais e biológicas) e os demais em matemática, física e/ou pedagogia. Por se tratarem de disciplinas de pós-graduação, alguns destes sujeitos já tiveram experiência na área da docência enquanto outros ainda estão em processo, sem nunca terem ministrado aulas. A experiência varia de nenhum até vinte e três anos lecionando, mas de forma geral, a grande parte se encontra em um período de nenhuma experiência até quatro anos.

Tendo em conta o descrito, foi definida como suposição inicial que, a maioria dos professores quando planejam suas aulas, ou seja, quando fazem desenhos microcurriculares tais como UD e sequências de ensino, reduzem as propostas a um ativismo e,portanto, os documentos não refletem os componentes do CDC ou pode-se dizer que ainda é um CDC incipiente. Para mostrar o suposto, se faz uma análise dedutiva considerando como matriz os critérios dos Quadros 1 e 2. Após, foram consideradas as tendências do CDC para identificar o inventário de crenças pedagógicas/didáticas de forma implícita ou explícita dentro dos quatorze documentos. Tendo em conta o descrito, foram realizadas as seguintes fases:

- Fase 1: Análise do conteúdo dos documentos para identificar componentes 
do CDC e para caracterizar os critérios que têm maior predomínio nos documentos (análise de palavras, frases, conceitos - unidades de registro-, e parágrafos - unidades de contexto-). Assim, resulta a categorização das unidades de registro e de contexto a partir dos componentes do CDC.

- Fase 2: Inventário de crenças pedagógicas/didáticas e científicas dos professores (imagem da ciência, teorias subjetivas da aprendizagem, modelo didático pessoal, e enfoque curricular, etc., segundo o referido na matriz).

\section{RESULTADOS E DISCUSSÃO}

Os resultados e sua discussão são descritos tendo em consideração as categorias: conhecimento / crenças do disciplinar; conhecimento / crenças do metadisciplinar; conhecimento / crenças do psicopedagógico e; conhecimento / crenças do contexto escolar, que nos permitem identificar os componentes do CDC e inferir o inventário das crenças pedagógicas/didáticas. O resumo dos resultados é apresentado nos Quadros 3 e 4.

Quadro 3 - Análise do Grupo A de Professores

\begin{tabular}{|c|c|c|c|c|c|}
\hline Grupo & $\begin{array}{c}\text { Conhecimento } \\
\text { / Crenças do } \\
\text { Contexto }\end{array}$ & $\begin{array}{c}\text { Conhecimento } \\
\text { / Crenças do } \\
\text { Disciplinar }\end{array}$ & $\begin{array}{c}\text { Conhecimento } \\
\text { / Crenças do } \\
\text { Metadisciplinar }\end{array}$ & $\begin{array}{c}\text { Conhecimento } \\
\text { / Crenças do } \\
\text { Psicopedagógico }\end{array}$ & $\begin{array}{c}\text { Conhecimento } \\
\text { / Método } \\
\text { Investigativo }\end{array}$ \\
\hline 1 & $\begin{array}{c}\text { Em } \\
\text { Partes }\end{array}$ & $\begin{array}{c}\text { Substantivo e } \\
\text { sintático }\end{array}$ & Presente & Presente & Presente \\
\hline 2 & $\begin{array}{c}\text { Não } \\
\text { Presente }\end{array}$ & $\begin{array}{c}\text { Sintático } \\
\text { (presente no } \\
\text { experimento) }\end{array}$ & $\begin{array}{c}\text { Pouco } \\
\text { presente }\end{array}$ & $\begin{array}{c}\text { Não } \\
\text { Presente }\end{array}$ & $\begin{array}{c}\text { Pouco } \\
\text { presente }\end{array}$ \\
\hline 3 & $\begin{array}{c}\text { Não } \\
\text { Presente }\end{array}$ & $\begin{array}{c}\text { Sintático } \\
\text { (presente no } \\
\text { experimento) }\end{array}$ & $\begin{array}{c}\text { Presente } \\
\text { em partes }\end{array}$ & $\begin{array}{c}\text { Pouco } \\
\text { Presente }\end{array}$ & Presente em \\
Partes
\end{tabular}

Fonte: Autoria Própria. 
Quadro 4 - Análise do Grupo B de Professores

\begin{tabular}{|c|c|c|c|c|}
\hline Grupo & $\begin{array}{c}\text { Conhecimento / Crenças } \\
\text { do Contexto }\end{array}$ & $\begin{array}{l}\text { Conhecimento } \\
\text { / Crenças do } \\
\text { Disciplinar }\end{array}$ & $\begin{array}{l}\text { Conhecimento } \\
\text { / Crenças do } \\
\text { Metadisciplinar }\end{array}$ & $\begin{array}{l}\text { Conhecimento } \\
\text { / Crenças do } \\
\text { Psicopedagógico }\end{array}$ \\
\hline 1 & $\begin{array}{l}\text { Presente de forma } \\
\text { completa }\end{array}$ & $\begin{array}{l}\text { Substantivo } \\
\text { e sintático }\end{array}$ & Presente & Presente \\
\hline 2 & Em partes & $\begin{array}{l}\text { Substantivo } \\
\text { e sintático }\end{array}$ & $\begin{array}{l}\text { Presente } \\
\text { em partes }\end{array}$ & Presente \\
\hline 3 & Em partes & Substantivo & Pouco presente & Presente \\
\hline 4 & Em partes & Sintático & Pouco presente & Presente em partes \\
\hline 5 & Pouco presente & Substantivo & Pouco presente & Presente em partes \\
\hline 6 & Pouco presente & Substantivo & $\begin{array}{l}\text { Presente } \\
\text { em partes }\end{array}$ & Presente \\
\hline 7 & Em partes & $\begin{array}{l}\text { Substantivo } \\
\text { e sintático }\end{array}$ & $\begin{array}{l}\text { Presente } \\
\text { em partes }\end{array}$ & Presente em partes \\
\hline 8 & Não claro & $\begin{array}{l}\text { Substantivo } \\
\text { e sintático }\end{array}$ & Pouco presente & Presente \\
\hline 9 & Pouco presente & $\begin{array}{l}\text { Substantivo } \\
\text { e sintático }\end{array}$ & Pouco presente & Presente \\
\hline
\end{tabular}

Fonte: Autoria Própria.

Categoria conhecimento / crenças do disciplinar, pelo grupo A: Segundo os resultados do Quadro 3, nesta categoria, o Grupo A, que trabalhou com o modelo didático de ensino por investigação, tem o predomínio do conhecimento sintático ou procedimental, sendo ressaltadas nas sequências de ensino atividades focadas em trabalhos práticos de laboratório que partem de uma pergunta de pesquisa escolar. A maioria delas apresenta os instrumentos e o roteiro que deve ser feito para resolver a pergunta de pesquisa escolar, o que passa a ideia de que os professores têm uma visão de ciência indutiva, que parte das observações de fenômenos, mas ainda assim dá a possibilidade para que os alunos expressem suas ideias iniciais como hipóteses de partida.

No Grupo A, a maioria manifesta que as teorias devem ser demonstradas através dos experimentos; só um subgrupo tem visão mais hipotético-dedutiva, dando a possibilidade que os alunos proponham suas hipóteses, seus materiais, seus desenhos experimentais. Sobre os saberes substantivos necessários para abordar a pergunta da pesquisa, somente um grupo faz ênfases nas teorias e princípios necessários para resolvê-la, os demais enfatizam conceitos relacionados com a pergunta de pesquisa. 
Categoria conbecimento / crenças do disciplinar, pelo grupo B: Dos nove subgrupos, que tinham opção em propor o modelo didático, só um deles aborda o conhecimento sintático fazendo ênfases nos instrumentos que usa a química para construir seu conhecimento, como é introduzido e aceito na comunidade científica. Os demais, só propõem atividades como tal, mas que não permitem aos alunos refletir sobre a forma como a ciência é construída pela comunidade de cientistas. Neste grupo, todos os subgrupos manifestam o conteúdo substantivo ou declarativo sobre tudo em relação aos conceitos e só um grupo apresenta as teorias e princípios próprios para o desenvolvimento da disciplina e como um corpo inter-relacionado de conceitos, teorias, paradigmas da disciplina.

Em geral, para os dois grupos, o conhecimento substantivo é manifestado pela definição de conceitos principalmente, como os enunciados nos Quadros 5 e 6. Na maioria dos subgrupos do grupo B e em dois subgrupos do A, há uma proposta de um enfoque mais interdisciplinar, sendo enunciados além dos conteúdos disciplinares, conteúdos associados a assuntos históricos, econômicos, políticos, sociais, tecnológicos e ambientais.

Quadro 5 - Conteúdos substantivos propostos nos desenhos curriculares Grupo A (SB: Subgrupo)

\begin{tabular}{|c|c|c|c|c|}
\hline SG & $\begin{array}{l}\text { Pergunta } \\
\text { de pesquisa } \\
\text { escolar }\end{array}$ & Conteúdo geral & Conceitos específicos & $\begin{array}{l}\text { Outros } \\
\text { conteúdos }\end{array}$ \\
\hline 1 & $\begin{array}{l}\text { Como evitar a } \\
\text { producção da } \\
\text { chuva ácida? }\end{array}$ & $\begin{array}{l}\text { Transformação } \\
\text { química }\end{array}$ & $\begin{array}{c}\text { Transformação / } \\
\text { conservação, equaç̃ões, } \\
\text { balanceamento, moléculas, }\end{array}$ & $\begin{array}{l}\text { Socioambientais, } \\
\text { históricos, } \\
\text { econômicos, } \\
\text { políticos }\end{array}$ \\
\hline 2 & $\begin{array}{c}\text { Precisamos nos } \\
\text { higienizar? }\end{array}$ & $\begin{array}{c}\text { Higiene, } \\
\text { saponificação }\end{array}$ & Saponificação & --- \\
\hline 3 & ----------- & $\begin{array}{l}\text { Transformação } \\
\text { química }\end{array}$ & $\begin{array}{l}\text { Transformação } \\
\text { (física e química) }\end{array}$ & ---- \\
\hline 4 & $\begin{array}{c}\text { E se o petróleo } \\
\text { acabasse? }\end{array}$ & Polímeros & $\begin{array}{l}\text { Polímeros, estrutura } \\
\text { química, propriedade } \\
\text { físicas e químicas }\end{array}$ & $\begin{array}{l}\text { Contextualiza } \\
\text { o conceito de } \\
\text { polímeros, } \\
\text { suas utilidades } \\
\text { no cotidiano, } \\
\text { influências } \\
\text { sociais e } \\
\text { históricas. }\end{array}$ \\
\hline 5 & $\begin{array}{c}\text { Teor de álcool } \\
\text { na gasolina }\end{array}$ & Álcool & $\begin{array}{l}\text { Polaridade, não } \\
\text { polaridade, misturas } \\
\text { miscíveis e imiscíveis }\end{array}$ & ---- \\
\hline
\end{tabular}

Fonte: Autoria Própria. 
Quadro 6 - Conteúdos substantivos propostos nos desenhos curriculares Grupo B (SB: Subgrupo)

\begin{tabular}{|c|c|c|c|c|}
\hline SG & $\begin{array}{l}\text { Pergunta } \\
\text { de pesquisa } \\
\text { escolar }\end{array}$ & Conteúdo geral & Conceitos específicos & Outros conteúdos \\
\hline 1 & $\begin{array}{l}\text { Determinação } \\
\text { do tamanho da } \\
\text { molécula de } \\
\text { ácido oleico }\end{array}$ & $\begin{array}{l}\text { Atomismo / } \\
\text { equivalentismo }\end{array}$ & Quantidade de substância, mol & ---n--- \\
\hline 2 & --------- & Transgenia & Transgênese & $\begin{array}{l}\text { Econômicos, } \\
\text { políticos, sociais, } \\
\text { tecnológicos }\end{array}$ \\
\hline 3 & -- & $\begin{array}{l}\text { Efeito } \\
\text { fotoelétrico }\end{array}$ & $\begin{array}{l}\text { Conservação da energia } \\
\text { mecânica, corrente elétrica, } \\
\text { efeito fotoelétrico, quantidade } \\
\text { de momento linear, trabalho }\end{array}$ & --- \\
\hline 4 & --- & Eletrostática & $\begin{array}{l}\text { Cargas, atração/repulsão entre } \\
\text { as cargas e eletrização por } \\
\text { atrito, contato e indução }\end{array}$ & ---- \\
\hline 5 & -- & $\begin{array}{l}\text { Função de } \\
\text { primeiro grau }\end{array}$ & $\begin{array}{l}\text { Função do primeiro grau, suas } \\
\text { definições, leis e propriedades }\end{array}$ & - \\
\hline 6 & ----------- & Biodiesel & $\begin{array}{l}\text { Fontes de energia, impactos } \\
\text { ambientais, motor diesel, } \\
\text { sustentabilidade, efeito estufa, } \\
\text { saúde humana, composição } \\
\text { química, transformação } \\
\text { de energia }\end{array}$ & $\begin{array}{l}\text { Econômicos, } \\
\text { políticos, sociais, } \\
\text { tecnológicos e } \\
\text { ambientais }\end{array}$ \\
\hline 7 & -------- & Astronomia & $\begin{array}{l}\text { Visão topocêntrica da } \\
\text { esfera celeste, movimento } \\
\text { aparente do Sol }\end{array}$ & ----------- \\
\hline 8 & ----------- & $\begin{array}{l}\text { Números } \\
\text { racionais }\end{array}$ & $\begin{array}{l}\text { Origens dos } \\
\text { números, frações }\end{array}$ & -- \\
\hline 9 & --- & Estações do ano & $\begin{array}{l}\text { Movimentaçães da Terra, } \\
\text { movimento aparente do Sol, } \\
\text { duração do ano, equinócio } \\
\text { e solstício, as estações e o } \\
\text { movimento de translação }\end{array}$ & --- \\
\hline
\end{tabular}

Fonte: Autoria Própria.

Categoria conhecimento / crenças do metadisciplinar, grupo A e B: só dois subgrupos, um de cada grupo, propõem aspectos relacionados com os mecanismos de produção do conhecimento químico, seus obstáculos epistemológicos; as formas de vida das comunidades científicas; os debates e controvérsias dadas entre as teorias atomistas; as revoluções científicas e experimentos cruciais; as biografias dos personagens; há propostas de análises de textos originais. Os demais subgrupos não abordam critérios histórico/epistemológicos pelo ensino das temáticas dentro das suas disciplinas. 
Um subgrupo do grupo A e três do grupo B abordam interações da disciplina com a sociedade, a tecnologia, a política, quando abordam problemas escolares mais interdisciplinares com tendência ao ambiental, tais como o problema dos combustíveis, a chuva ácida, os transgênicos. Um dos grupos que aborda um tema disciplinar inclui elementos contextuais, históricos, ambientais, o que mostra que as interações da disciplina não têm a ver só com a definição de um problema interdisciplinar ou ambiental, embora na maioria das vezes os temas ambientais favoreçam a interdisciplinaridade e um ensino mais contextualizado.

Categoria conhecimento / crenças do psicopedagógico do grupo $A$ : os cincos subgrupos (SG) deste grupo trabalharam o desenho microcurricular com o modelo de ensino por/como investigação (EpI), que segundo o resumido no Quadro 2, a maioria deles se focaliza no Ensino por descobrimento dirigido, com visão internalista. Esta tendência é manifestada na maioria dos SG a partir das atividades propostas nos documentos. Eles não descrevem o referencial do modelo a usar, simplesmente são desenvolvidas atividades para fazê-las de forma individual e coletiva, as quais definem um problema de pesquisa escolar, e o que é pretendido com estas (como colocado no Quadro 7).

Quadro 7 - Aspectos do modelo de ensino por investigação identificado nos desenhos do Grupo A

\begin{tabular}{|c|c|c|c|}
\hline SG & Pergunta de pesquisas & 0 que pretendem & Visão de Epl \\
\hline 1 & $\begin{array}{l}\text { Como evitar a } \\
\text { produção da } \\
\text { chuva ácida? }\end{array}$ & $\begin{array}{c}\text { Resolver problemas, expressar as } \\
\text { ideias próprias (modelos mentais como } \\
\text { as primeiras, hipóteses); estabelecer } \\
\text { relaçõesCTSA; propor experimentos, inferir, } \\
\text { explicar, passando } \\
\text { por níveis de transição. }\end{array}$ & $\begin{array}{l}\text { Internalista / } \\
\text { Externalista }\end{array}$ \\
\hline 2 & $\begin{array}{c}\text { Precisamos nos } \\
\text { higienizar? }\end{array}$ & $\begin{array}{c}\text { Analisar duas situações contextualizadas a } \\
\text { partir de um laboratório tipo } \\
\text { "receita de cozinha" }\end{array}$ & Internalista \\
\hline 3 & Não é explicitado & $\begin{array}{l}\text { Identificar as ideais prévias, para o qual } \\
\text { propõe um experimento centrado nas } \\
\text { observações; o experimento é para } \\
\text { “desmitificar concepções equivocadas” e } \\
\text { superar as ideias previas por novas ideias. }\end{array}$ & Internalista \\
\hline 4 & $\begin{array}{c}\text { E se o petróleo } \\
\text { acabasse? }\end{array}$ & $\begin{array}{c}\text { Propõe ao aluno elaborar descrições, } \\
\text { comparações, deduções e explicações. } \\
\text { Parte de um roteiro centrado nas } \\
\text { observações; Sequência de atividades } \\
\text { orientadas como um passo a passo. }\end{array}$ & Internalista \\
\hline 5 & $\begin{array}{l}\text { Teor de álcool } \\
\text { na Gasolina }\end{array}$ & $\begin{array}{l}\text { Demonstrar teorias e fenômenos; } \\
\text { testar hipóteses; desenvolver } \\
\text { habilidades de observação. }\end{array}$ & Internalista \\
\hline
\end{tabular}

Fonte: Autoria própria. 
Os cinco subgrupos têm uma visão internalista no sentido que a abordagem do modelo de EpI é centrado nos conceitos, teorias e atividades experimentais. Nos subgrupos 2, 3, 4, e 5 a ideia do experimento escolar é para "demonstrar teorias e testar hipóteses”, havendo ainda uma visão positivista porquanto as atividades devem partir das observações orientadas pelo professor. Somente um SG (SG1), além de abordar mais teorias do que conceitos, aborda a visão externalista, a qual é evidente no referencial do documento analisado, complementado com o referencial do CDC. O SG1 descreve que trabalha um currículo intencional centrado nas relações CTSA a partir do modelo de ensino por pesquisa "para que os alunos façam análises dos impactos da ciência (e não só a vejam como conteúdos ou conceitos isolados), focalizando conhecimentos, capacidades, atitudes e valores; saberes pessoais e sociais". Este SG1 é o único que de forma explícita manifesta como seria feito o processo de avaliação dos aprendizados e da UD.

Em geral, os SG do grupo A consideram as ideias prévias, entretanto o SG1 as descreve como modelos mentais (conceito que atualmente é mais usado na literatura) que passam por níveis de transição, ou seja, a aprendizagem do alunado é um processo lento, contínuo, que passa por níveis, e não é uma simples "superação das ideias prévias por outras".

Categoria conhecimento / crenças do psicopedagógico do grupo B: Neste grupo são explícitos, na maioria dos SG, os referenciais teóricos da proposta, diferentemente do grupo A. Os referenciais descritos são: no SG1 "CIMA: contextualização, indagação, modelização, argumentação"; o SG3 eo SG9 a aprendizagem significativa; o enfoque CTS no SG5, e o SG6 o enfoque IIR: Ilha interdisciplinar de Racionalidade" de Fourez. Destes cinco subgrupos, como no desenvolvimento da sequência e da UD, vão sendo evidenciadas aplicações do referencial teórico; pelos demais SG não é evidente sua articulação. Nota-se assim, um amadurecimento maior em relação aos integrantes do grupo A, pois eles argumentam sua prática com a teoria, colocando em prática os referenciais estudados ao longo de sua formação.

Dentro da estrutura da UD, só o SG1 responde a todas as perguntas do desenho curricular (Figura 1) articulando o ensino e a avaliação. Os demais SG descrevem as perguntas sobre o que e como ensinar. Em geral, as atividades dos subgrupos promovem nos alunos capacidades e habilidades pela resolução de problemas, só que não são organizadas de forma progressiva. O SG1 é o único que apresenta tabelas que descrevem os níveis pelos quais podem ir passando os alunos (como uma trama de transição).

Quatro dos nove subgrupos expressam a avaliação das aprendizagens, mas suas atividades ficam no final do processo; o SG1, ao abordar o ensino/avaliação de forma simultânea, faz com que a avaliação seja permanente, enunciando além da avaliação da UD, porque o desenho é argumentado como uma hipótese que o professor tenta validar. Portanto, a dita proposta vai sendo melhorada na sua implementação tendo em conta o referencial usado.

Em geral nesta categoria, os grupos A e B têm diferenças nos conhecimentos/crenças evidenciados: no grupo A, quatro dos cinco SG não explicitam as teorias educativas; o conhecimento do currículo; os modelos de desenvolvimento e aprendizagem do alunado; os modelos mentais dos alunos; as estratégias de ensino; as metodologias e as formas de organização dos grupos; os critérios e formas de avaliação, portanto dão mais ênfases nas atividades. 
Para o grupo B, mesmo sendo manifestos na maioria dos subgrupos o enfoque do modelo didático e o referencial teórico que têm escolhido, não são facilmente evidenciados. Parece que há crença que ao fazer um desenho curricular não são necessários os elementos teóricos que a validam. O que permite dizer que as sequências de ensino e as UD têm somente atividades ou talvez não seja fácil para o professor fazer essas articulações entres os saberes acadêmicos e os saberes da prática profissional, pelo qual os conhecimentos/ crenças do pedagógico / didático não estão sendo articulados nem estão sendo levados à prática de forma desejável.

Categoria conhecimento / crenças do contexto escolar dos grupos $A$ e B: Em geral, tanto para os subgrupos dos grupos A e quanto para os do B é a categoria em que menos elementos são descritos na proposta. Só é descrito o nome da escola (subgrupos de A) que tem a ver com a pergunta onde se ensina e o nível dos alunos ao qual será ensinado (a quem ensina?),mas não descrevem aspectos relacionados com as normas de funcionamento institucional escolar, normativas nacionais nem locais. Não são descritos aspectos da configuração cultural, política, ideológica, entre outras, que são próprias da instituição escolar. Para os casos dos subgrupos que trabalham um ensino mais contextualizado, é apresentada a sequência e a UD como um problema escolar proposto, como uma problemática própria do contexto local. Esta categoria é importante porque na maioria das vezes não se tem diferenças dos contextos nos quais são implementados os processos de ensino ou o professorado não sabe como integrá-los.

\section{CRITÉRIOS PARA FORMAC̣̃̃O DE PROFESSORES}

De acordo com os resultados e suas análises, considerando o referencial citado, recomenda-seque a formação de professores de ciências da natureza e matemática deve seguir fortalecendo-se nos seguintes aspectos:

- Nos conhecimentos/crenças disciplinares, já que pelo descrito, este responde ao que ensinar. É fundamental e claro nos desenhos dos professores que a lógica que tem sido estruturada na própria disciplina ao longo dos anos permite aos professores identificar facilmente os conceitos ao ensinar, só que predomina, na maioria dos casos, uma visão disciplinar, ou seja, um ensino de conteúdos na maioria das vezes sem uma justificativa. Nos subgrupos de professores que pensaram em propostas mais interdisciplinares (grupo B), eles definem "o que ensinar" a partir das problemáticas do cotidiano ou do mundo, o que dá mais sentido aos conceitos e às teorias que na maioria dos casos são trabalhados. Os professores que trabalham com enfoques interdisciplinares encontram como justificar melhor o que devem ensinar e articular conceitos, princípios, teorias das ciências e da matemática. Como afirmam Parga e Pinzón (2014, p. 43), “os conteúdos deveriam descentralizar-se da lógica das disciplinas para orientar-se a partir da lógica dos problemas existentes nas escolas e a partir da lógica do pensamento dos que desejam aprender".

- Para os conhecimentos/crenças disciplinares não basta uma formação com ênfases nos conteúdos; os programas de formação inicial e continuada devem pensar em formar professores para ensinar não apenas conteúdos, pois o que o professor faz é reescrever e reduzir conteúdos a meras definições: ou seja, a disciplina fica totalmente descontextualizada da 
própria disciplina -sem contexto teórico, histórico, social. É preciso seguir trabalhando de forma explícita os conteúdos sintáticos ou procedimentais, que são parte das disciplinas: os métodos de construção, os instrumentos que usa a disciplina para construir seu conhecimento, a forma como é introduzida e aceita uma teoria, por exemplo, na comunidade científica.

- Nos conhecimentos/crenças metadisciplinares, a maioria dos professores identifica a história da disciplina mais de forma anedótica, historiográfica, sem ter clareza da história interna e externa desta; considera a epistemologia como uma disciplina, mas para ensinar e não uma metadisciplina, que permite compreender os mecanismos de produção do conhecimento; os obstáculos epistemológicos; as formas de vida das comunidades científicas; os debates e controvérsias do passado e do pressente; as revoluções científicas e o papel dos experimentos; as vidas e biografias dos cientistas, e os textos originais (superando visões do século XIX e XX e pensando numa epistemologia para o século XXI). O professor necessita levarem conta estes conhecimentos/crenças, ter a capacidade para identificar os modelos mentais dos alunos, ensinar a natureza da disciplina, fazer abordagens intere transdisciplinares, abordar problemas da história e atuais, estabelecer relações da ciência com a sociedade, a política, a economia, além de incluir aspectos éticos e morais no ensino, entre outros.

- Nos conhecimentos/crenças psicopedagógicos, como foi evidenciado nos desenhos curriculares, é visto como um conhecimento reduzido só a atividades; na maioria das vezes os professores não usam os referenciais aprendidos na universidade, durante sua formação. Ao ser usado, é descrito de forma desarticulado da UD e da sequência de ensino proposta. Pode-se supor que o professorado não considere necessário expressar nem interpretar tais referentes; o conhecimento do currículo; os modelos de desenvolvimento e aprendizagem do alunado; os modelos mentais; as estratégias de ensino; as metodologias e formas de organização dos grupos; os critérios e formas de avaliação no documento da proposta curricular planejada. Quando são propostas as atividades, estas são apresentadas sem níveis evolutivos, não se explicita se as atividades têm relação com os objetivos propostos, não é evidente nos desenhos como os temas ao ensinar pretendem desenvolver determinadas habilidades ou capacidades. Percebe-seque na formação inicial e continuada dos professores de ciências e matemática, processos de ensino inter-relacionados, que lhes permitam ir refletindo sobre os critérios teóricos e práticos.

- Conhecimentos / crenças do contexto. Esta categoria deve ser trabalhada não somente para que o professor identifique as normas gerais, ele deve saber usá-las nos próprios desenhos, porque uma característica que os desenhos curriculares apresentam é sua contextualização, são próprios para cada escola, para cada grupo, por isso os modelos didáticos devem ser pensados como modelos contextuais e não gerais.

Os critérios anteriores são elementos para se prosseguir analisando e pesquisando qual é a melhor estrutura curricular dos programas de formação dos professores a partir dos conhecimentos/crenças enunciados, tendo em conta suas articulações e integrações. Não se pode continuar oferecendo programas 
nos quais, cada campo dos conhecimentos/crenças esteja desligado um de outro. Não basta mudar as disciplinas ao ensinar nos programas, sem pensar que são saberes e conhecimentos/crenças que devem se articular a partir de um currículo integrado e não parcializado, porque,para a maioria dos professores,estes que serão consolidados em sua prática profissional estão separados, dispersos, fragmentados. Por isso, concordando com Parga e Pinzón (2014, p. 50),

[...] a formação deve articular-se com os conteúdos acadêmicos, disciplinares, metadisciplinares, psicopedagógicos e contextuais. Neste sentido, o conhecimento fundamental que é próprio do professorado é o conhecimento didático do conteúdo, CDC, que é um conhecimento estruturador e emergente da prática profissional.

É necessário formar os professores para trabalhar de forma coletiva e não fazer desenhos individualizados; é preciso fortalecer a formação acadêmica e cidadã, institucional, individual e profissional, a qual se consegue através das aprendizagens contínuas e do trabalho coletivo/colaborativo entre colegas. Isto mostra que o professor deve saber qual é seu CDC, como deve melhorá-lo a propósito de cada tema que vai ensinar. Além dos pontos já elencados:

- Deve-se fomentar práticas de ensino refletivas/investigativas para que sejam analisadas e implementadas;

- Os programas não atendem, na maioria das vezes, às necessidades individuais, somente necessidades e contextos escolares diversos que pouco consideram o particular das instituições e do professorado. Portanto universidade e escola devem trabalhar articuladamente com projetos conjuntos que consideram as problemáticas locais e específicas.

- Fomentar modelos pedagógicos/didáticos na própria universidade que sejam interdisciplinares e transdisciplinares.

- É necessário sintonizar o currículo de formação de professores com as demandas, as expectativas e a pertinência do contexto social e com quem o integra, fazendo um trabalho metadisciplinar.

Quaisquer que sejam os elementos propostos pela formação de professores, estes devem resultar da interação e do trabalho conjunto entre as pesquisas produzidas nas didáticas específicas, nas necessidades profissionais dos professores e nos problemas dos contextos escolares e sociais.

\section{CONSIDERAC̣ÕES FINAIS}

Segundo os resultados e as análises realizadas nos desenhos das UD e sequências de ensino curriculares, os conhecimentos/crenças predominantes nos professores do estudo mostram uma tendência para um saber disciplinar centrado em conceitos, na maioria dos casos desarticulados. Embora identifiquem aspectos do psicopedagógico, ainda não são evidentes como os referentes a este saber podem melhorar o desenho. Quando são usados poderiam ser superadas as visões fragmentadas e atomizadas do conteúdo ao ensinar e quando só se consideram as estratégias do ensino, os desenhos produzidos ficam centrados no ativismo dando a ideia de uma ciência indutivista/positivista. 
Os conhecimentos/crenças metadisciplinares e contextuais são usados com menor frequência, sobretudo quando são abordados temas a partir das problemáticas ambientais e contextuais dos alunos e da comunidade. Portanto, o trabalho com enfoques didáticos transversais e interdisciplinares permitem que nos desenhos sejam integrados de maneira sistêmica os diversos componentes do CDC.

Este trabalho mostrou que a maioria dos professores do estudo, quando planejam suas aulas, ou seja, quando fazem desenhos microcurriculares tais como UD e sequências de ensino, reduzem as propostas a um ativismo e, portanto, os documentos não refletem todos os saberes nem os conhecimentos/crenças que eles precisam e que possuem como profissionais da docência. Assim, a pesquisa deve continuar para poder analisar na ação, como é assumido pelos professores, o que planejam e como os saberes de referência ou acadêmicos são colocados em jogo para resolver problemas da prática docente.

Finalmente, para superar as falências que atualmente se têm na formação de professores e no ensino de ciências e matemática, uma das propostas para os programas de formação inicial e continuada é de considerarem os componentes do CDC como o conhecimento estruturador e emergente da prática profissional, como exemplo de algumas instituições que já o fazem. Isto permite colocar em ação os conhecimentos/crenças dos professores, os quais podem estar fundidos em um currículo orientado na interação e em um currículo global que reflete as problemáticas próprias das instituições e da sociedade, mas em todo caso, em que os conteúdos, objetivos, estratégias dependam do problema escolar que se vai se abordar, evitando conteúdos, objetivos e metodologias impostos por outros (neste caso pela universidade ou pelo programa de formação).

\section{AGRADECIMENTO}

À Prof. Dra. Silvia Zuliani (UNESP - Bauru/SP) pelo apoio na escrita e revisão deste texto.

\section{REFERÊNCIAS}

CAAMAÑO, A. Enseñar química mediante la contextualización, la indagación y la modelización. Alambique: didáctica de las ciencias experimentales, Barcelona: IRIF; Barcelona: Graó, n. 69, p. 21-34, jul. 2011.

CAAMAÑO, A. La investigación escolar es la actividad que mejor integra el aprendizaje de los diferentes procedimientos científicos. In: PEDRINACI, E.; CAAMAÑO, A; CAÑAL, P.; DE PRO, A. (org.). El desarrollo de la competencia científica. Espanha: Graó, p. 127-146, 2012a.

CAAMAÑO, A. La elaboración y evaluación de modelos científicos escolares es una forma excelente de aprender sobre la naturaleza de la ciencias. In: PEDRINACI, E.; CAAMAÑO, A; CAÑAL, P.; DE PRO, A. (org.). El desarrollo de la competencia científica. Espanha: Graó, p. 105-126, 2012b. CAMPANARIO, J.M.; MOYA, A. ¿Cómo enseñar ciencias? Principales tendencias y propuestas. Enseñanza de las ciencias, Barcelona: UAB,v. 17, n.2, p. 179-192, 1999.

CAÑAL, P. El análisis didáctico de la dinámica del aula: tareas, actividades y estrategias de enseñanza. In: PALACIOS F. J. P.; CAÑAL, P. Didáctica de las ciencias experimentales.España: Editorial Marfil, p. 209-238, 2000.

COUSO, D. Las secuencias didácticas en la enseñanza y aprendizaje de las ciencias: modelos para su diseño y validación. In: CAAMAÑO, A. (org.). Didáctica de la física y química. Barcelona. Graó, cap. 3, 2011. 
GALEANO, M. Estrategias de investigación social cualitativa: el giro en la mirada. Medellín: La Carreta editores. 2012.

MARCELO, C. A identidade docente: constantes e desafios. Formação Docente, Belo Horizonte: ANPED; Belo Horizonte: Autêntica, v. 01, n. 01, p. 109-131, 2009.

MORA, W.M.; PARGA, D.L. El conocimiento didáctico del contenido en química: integración de las tramas de contenido histórico-epistemológicas con las tramas de contexto-aprendizaje. Tecné, episteme y didaxis. Bogotá: Universidad Pedagógica Nacional, n. 24, p. 56-81, 2º sem. 2008.

MORA, W.M.; PARGA, D.L. Aportes al CDC desde el pensamiento complejo. In: GARRITZ, A.; LORENZO, M. G.; ROSALES, S. F. D. (org.). Conocimiento didáctico del contenido: una perspectiva latino-americana. Saarbrücken, Alemanha: Editorial Académica Española, p. 100-143,2014. MOSQUERA, C.; MORA, W.; GARCÍA, A. Conceptos fundamentales de la química y su relación con el desarrollo profesional del profesorado. Bogotá: Universidad Distrital Francisco José de Caldas, 2003.

MUNFORD, D.; LIMA, M. E. C. C. Ensinar ciências por investigação: em que estamos de acordo? Ensaio: pesquisa em educação em ciências, Belo Horizonte: UFMG; Belo Horizonte: CECIMIG, v. 9, n. 1, p. 72-89, 2007.

PARENTE, A. G. L. Práticas de investigação no ensino de ciências: percursos de formação de professores. 2012. 234f. Dissertação (Mestrado em Educação para a Ciência) - Faculdade de Ciências, Universidade Estadual Paulista, 2012.

PARGA, D. L.; MORA, W. M. El PCK, un espacio de diversidad teórica: conceptos y experiencias unificadoras en relación con la didáctica de los contenidos en química. Educación química, México: Universidad Nacional Autónoma de México; México: Elsevier, v. 25, n.3, p. 332-342, jun. 2014.

PARGA, D. L.; PINZÓN, Y. A. El currículo del programa de formación de profesores en la interfaz universidad escuela. In: MARTÍNEZ, L. F.; PARGA, D.L. (org.).Formación permanente de profesores en la interfaz universidad-escuela: currículo, fundamentos y roles. Una experiencia en construcción. Bogotá: Editorial Universidad pedagógica Nacional, p. 39-71, 2014.

SANMARTÍ. N. El diseño de unidades didácticas. In: PALACIOS F. J. P.; CAÑAL, P. Didáctica de las ciencias experimentales. España: Editorial Marfil, p. 239-266, 2000.

SHULMAN, L. S. Knowledge and teaching: foundations of the new reform. Harvard Educational Review, v. 57, n. 1, p. 1-22, fev. 1987.

TARDIF, M. Los saberes del docente y su desarrollo profesional. Madrid: Narcea Ediciones. 2004.

TORRES, J. Globalización e interdisciplinariedad: el currículo integrado. Madrid: Editorial Morata. 1994.

\section{Submetido em $17 / 10 / 2016$}

Aprovado em 18/10/2017

\section{Contato:}

Diana Lineth Parga Lozano

Universidad Pedagógica Nacional

Faculdade de Ciência e Tecnologia Departamento de Química

Rua 72 \#11-86 Local B, 4to. andar

Of. B430

Código Postal: 110221000

Bogotá -Colômbia 


\section{ANEXO 1}

Quadro 2 - Evolução das propostas de Ensino por/como investigação

\begin{tabular}{|c|c|c|c|c|c|c|c|}
\hline Categoria & & \multicolumn{3}{|c|}{ Internalista } & \multicolumn{3}{|c|}{ Externalista } \\
\hline Proposta & $\begin{array}{l}\text { Ensino por / } \\
\text { como } \\
\text { investigação }\end{array}$ & $\begin{array}{c}\text { Ensino por } \\
\text { descobrimento dirigido } \\
\text { (ou aprendizagem } \\
\text { como investigação) }\end{array}$ & $\begin{array}{l}\text { Investigação } \\
\text { dirigida }\end{array}$ & $\begin{array}{l}\text { Trabalhos de } \\
\text { investigação } \\
\text { (ou processo de } \\
\text { investigação } \\
\text { orientada) }\end{array}$ & $\begin{array}{l}\text { Ensino por } \\
\text { pesquisa }\end{array}$ & $\begin{array}{c}\text { Educar pela pesquisa } \\
\text { ou pesquisa na sala } \\
\text { de aula }\end{array}$ & $\begin{array}{l}\text { Investigação } \\
\text { escolar }\end{array}$ \\
\hline Autores & $\begin{array}{l}\text { Athayde (2003); } \\
\text { Acevedo (2004), } \\
\text { Munford e } \\
\text { Lima (2007); } \\
\text { Sá (2009). }\end{array}$ & $\begin{array}{c}\text { Gil Perez } \\
(1983,1986)\end{array}$ & $\begin{array}{c}\text { Gil Perez } \\
\text { e Castro (1996) }\end{array}$ & $\begin{array}{c}\text { Vilches, Solbes e } \\
\text { Gil Perez (2004); } \\
\text { Vilches, Marques, } \\
\text { Gil Perez e Praia } \\
\text { (2007) }\end{array}$ & $\begin{array}{l}\text { Cachapuz, Praia e } \\
\text { Jorge (2000),Cachapuz } \\
\text { e Gil-Pérez (2002); } \\
\text { Vasconcelos, Praia e } \\
\text { Almeida (2003) }\end{array}$ & $\begin{array}{l}\text { Lima (2004); Moraes } \\
\text { (2002); Moraes, } \\
\text { Galiazzi e Ramos, } \\
\text { (2002); Moraes, } \\
\text { Ramos e Galiazzi } \\
\text { [2004] }\end{array}$ & $\begin{array}{l}\text { Cañal e Porlán (1987); } \\
\text { Cañal (1999); Cañal } \\
\text { (2008); Izquierdo (2000) }\end{array}$ \\
\hline $\begin{array}{l}\text { Papel do } \\
\text { professor }\end{array}$ & $\begin{array}{c}\text { Levar os } \\
\text { alunos a } \\
\text { pensar, a } \\
\text { debater, a } \\
\text { justificar suas } \\
\text { ideias e a } \\
\text { aplicar seus } \\
\text { conhecimentos } \\
\text { em situações } \\
\text { novas. }\end{array}$ & $\begin{array}{c}\text { Analisar as ideias } \\
\text { dos alunos para sua } \\
\text { mudança conceitual e } \\
\text { metodológica. } \\
\text { Propor situações ou } \\
\text { atividades abertas. } \\
\text { Orientar as situações } \\
\text { de investigação. }\end{array}$ & $\begin{array}{l}\text { Caracterizar as } \\
\text { ideias dos alunos } \\
\text { (suas hipóteses) } \\
\text { as quais são } \\
\text { organizadores } \\
\text { na aula. }\end{array}$ & $\begin{array}{c}\text { Orientar a } \\
\text { investigação. } \\
\text { Alfabetiza } \\
\text { cientificamente, } \\
\text { com o enfoque } \\
\text { CTS. } \\
\text { Trabalhar na } \\
\text { perspectiva } \\
\text { ciência para a } \\
\text { cidadania. }\end{array}$ & $\begin{array}{l}\text { Trabalhar um currículo } \\
\text { CTSA, focalizando } \\
\text { conhecimentos, } \\
\text { capacidades, atitudes } \\
\text { e valores, saberes } \\
\text { pessoais e sociais. }\end{array}$ & $\begin{array}{l}\text { Investigador da } \\
\text { própria prática. }\end{array}$ & $\begin{array}{c}\text { Guia que desenvolvi } \\
\text { capacidades, destrezas } \\
\text { intelectuais, afetivas, } \\
\text { motoras; autonomia, } \\
\text { criatividade, cooperação, } \\
\text { espírito crítico, } \\
\text { objetividades, etc. }\end{array}$ \\
\hline Papel do aluno & $\begin{array}{l}\text { Aprender } \\
\text { conteúdos, e } \\
\text { habilidades: } \\
\text { argumentar, } \\
\text { interpretar, } \\
\text { analisar. }\end{array}$ & $\begin{array}{l}\text { Realizar atividades } \\
\text { práticas, predições, } \\
\text { comparações, } \\
\text { elaborar hipóteses e } \\
\text { contrastá-las. }\end{array}$ & $\begin{array}{l}\text { Trabalhar } \\
\text { problemas } \\
\text { abertos, }\end{array}$ & $\begin{array}{c}\text { Estar alfabetizado } \\
\text { cientificamente, e } \\
\text { imerso na cultura } \\
\text { científica. }\end{array}$ & $\begin{array}{c}\text { Fazer pesquisa } \\
\text { compartilhada para } \\
\text { resolver problemas } \\
\text { abertos. }\end{array}$ & $\begin{array}{c}\text { Despertar } \\
\text { politicamente para } \\
\text { criar soluções aos } \\
\text { problemas que } \\
\text { enfrenta. }\end{array}$ & $\begin{array}{l}\text { Aprender, sendo } \\
\text { protagonista da } \\
\text { investigação. }\end{array}$ \\
\hline Ensino & $\begin{array}{l}\text { Traz a escola } \\
\text { à prática dos } \\
\text { cientistas. } \\
\text { Desenvolve } \\
\text { habilidades } \\
\text { para resolver } \\
\text { problemas de } \\
\text { significância } \\
\text { social. }\end{array}$ & $\begin{array}{l}\text { Fundamentado no } \\
\text { paralelismo entre } \\
\text { desenvolvimento } \\
\text { conceitual e evolução } \\
\text { histórica da ciência. }\end{array}$ & $\begin{array}{l}\text { Atividades } \\
\text { baseadas nas } \\
\text { réplicas de } \\
\text { investigações dos } \\
\text { especialistas. }\end{array}$ & $\begin{array}{l}\text { Aproximação à } \\
\text { pratica cientifica, } \\
\text { com tratamentos } \\
\text { analíticos. }\end{array}$ & $\begin{array}{l}\text { Permite uma educação } \\
\text { científica "em, através e } \\
\text { sobre a ciência. } \\
\text { Deixa a perspectiva } \\
\text { internalista. }\end{array}$ & $\begin{array}{c}\text { Articular o aspecto } \\
\text { formal lexplicitaccão } \\
\text { dos conhecimentos } \\
\text { prévios e construção } \\
\text { de conceitos) e o } \\
\text { político, (desenvolve } \\
\text { a competência } \\
\text { social). }\end{array}$ & $\begin{array}{c}\text { Atividade complexa, } \\
\text { como a } \\
\text { própria ciência }\end{array}$ \\
\hline Aprendizagem & $\begin{array}{l}\text { Mudança } \\
\text { conceitual, } \\
\text { metodológica, } \\
\text { atitudinal e } \\
\text { axiológica. }\end{array}$ & $\begin{array}{l}\text { Dominar conceitos } \\
\text { Mudança conceitual, } \\
\text { próprio do modelo } \\
\text { construtivista, } \\
\text { através de mudança } \\
\text { da MS. }\end{array}$ & $\begin{array}{l}\text { Mudança } \\
\text { conceitual, } \\
\text { metodológica } \\
\text { e atitudinal, } \\
\text { promovendo } \\
\text { conflito cognitivo. }\end{array}$ & $\begin{array}{l}\text { Integração } \\
\text { dos aspectos } \\
\text { conceituais, } \\
\text { metodológicos } \\
\text { e axiológicos } \\
\text { (ou conceitos, } \\
\text { procedimentos e } \\
\text { atitudes). }\end{array}$ & $\begin{array}{l}\text { Integração dos saberes } \\
\text { dispersos do aluno, para } \\
\text { sistematizar, integrar, } \\
\text { sintetizar e comunicar. }\end{array}$ & $\begin{array}{l}\text { Construção de } \\
\text { conceitos científicos } \\
\text { e formação política } \\
\text { do aluno para sua } \\
\text { intervenção na } \\
\text { realidade. }\end{array}$ & $\begin{array}{l}\text { Modificação e } \\
\text { reestruturação do saber } \\
\text { progressivo dos alunos. }\end{array}$ \\
\hline Ciência & $\begin{array}{c}\text { Método de } \\
\text { pensamento. }\end{array}$ & $\begin{array}{l}\text { Tenta superar a } \\
\text { visão empirista / } \\
\text { indutivista. } \\
\text { Investigar é produzir } \\
\text { conhecimento. }\end{array}$ & $\begin{array}{l}\text { Atividade que } \\
\text { integra PLP e RP, } \\
\text { aprendizagem de } \\
\text { conceitos. } \\
\text { Envolve aspectos } \\
\text { metodológicos e } \\
\text { epistemológicos. }\end{array}$ & $\begin{array}{l}\text { Atividade } \\
\text { relacionada com } \\
\text { a tecnologia. }\end{array}$ & $\begin{array}{l}\text { Relação entre a } \\
\text { perspectiva internalista } \\
\text { e externalista. }\end{array}$ & $\begin{array}{l}\text { Conhecimento } \\
\text { institucionalizado } \\
\text { para pensar e } \\
\text { dialogar com } \\
\text { a realidade. }\end{array}$ & $\begin{array}{l}\text { Atividade humana, } \\
\text { possuidora de valores } \\
\text { próprios; não só } \\
\text { epistêmicos. }\end{array}$ \\
\hline Estratégia & $\begin{array}{l}\text { Atividades } \\
\text { concebidas } \\
\text { como } \\
\text { problemas. }\end{array}$ & $\begin{array}{c}\text { Trabalhar com } \\
\text { semelhança a prática } \\
\text { científica: predizer, } \\
\text { comparar, levantar } \\
\text { hipóteses. }\end{array}$ & $\begin{array}{l}\text { Integra TLP e RP, } \\
\text { aprendizagem } \\
\text { conceitual, tenta } \\
\text { superar a MS. }\end{array}$ & $\begin{array}{l}\text { Discussão dos } \\
\text { interesses da } \\
\text { investigação, } \\
\text { estudo qualitativo } \\
\text { da situação, } \\
\text { invenção de } \\
\text { conceitos e } \\
\text { formulação de } \\
\text { hipóteses, análise } \\
\text { de resultados e } \\
\text { sua comunicação, } \\
\text { sínteses, e sua } \\
\text { valorização. }\end{array}$ & $\begin{array}{l}\text { Planeja, desenvolve, } \\
\text { avalia e comunica. } \\
\text { Centrada no } \\
\text { experimento, trabalho } \\
\text { de campo, leitura, } \\
\text { debate, TIC's, etc. }\end{array}$ & $\begin{array}{l}\text { Articula os } \\
\text { problemas sociais } \\
\text { para questionar, } \\
\text { argumentar e } \\
\text { comunicar. }\end{array}$ & $\begin{array}{l}\text { Investigação } \\
\text { escolar. }\end{array}$ \\
\hline
\end{tabular}

